\title{
Mesh-covered (Roadsaver) stent as a new treatment modality for symptomatic or high-risk carotid stenosis
}

\author{
Roman Machnik ${ }^{1}$, Piotr Paluszek ${ }^{1}$, tukasz Tekieli², Karolina Dzierwa², Damian Maciejewski², \\ Mariusz Trystuła ${ }^{1}$, Andrzej Brzychczy ${ }^{1}$, Krzysztof Banaszkiewicz ${ }^{3}$, Robert Musiał ${ }^{4}$, Piotr Pieniążek ${ }^{1}$ \\ ${ }^{1}$ Department of Vascular Surgery and Endovascular Interventions, John Paul II Hospital, Krakow, Poland \\ ${ }^{2}$ Department of Interventional Cardiology, Institute of Cardiology, Jagiellonian University Medical College, John Paul Hospital, Krakow, \\ Poland \\ ${ }^{3}$ Department of Neurology, John Paul II Hospital, Krakow, Poland \\ ${ }^{4}$ Department of Anesthesiology and Intensive Medical Therapy, John Paul II Hospital, Krakow, Poland
}

Adv Interv Cardiol 2017; 13, 2 (48): 130-134

DOI: https://doi.org/10.5114/pwki.2017.68139

\begin{abstract}
A bstract
Introduction: Prevention of periprocedural stroke has a crucial role in carotid artery stenting (CAS) procedures.

Aim: To assess retrospectively 30-day safety and effectiveness of 41 procedures of internal and common carotid artery stenting using the Roadsaver double nitinol layer micromesh stent in 40 non-consecutive patients with symptomatic or high-risk carotid artery stenosis.

Material and methods: The patients were men $(n=31)$ and women $(n=9)$; mean age was $67.8 \pm 7.9$ years. Femoral access was used in 39 cases, whereas radial access was used in 2. Proximal $(n=27)$ or distal $(n=14)$ embolic neuroprotection was used.

Results: The Roadsaver stents (nominal diameter 7, 8 or $9 \mathrm{~mm}$, length 25 or $30 \mathrm{~mm}$ ) were implanted successfully in all cases. One minor stroke occurred after common carotid artery intubation with a guiding catheter (before stent deployment) and one transient postprocedural ischemic attack (TIA) of the ipsilateral cerebral hemisphere was observed. Internal/common carotid artery stenosis severity was evaluated by duplex Doppler. Maximal peak systolic velocity (PSV) before CAS was in the range: $2.0-7.0 \mathrm{~m} / \mathrm{s}$, mean: $3.9 \pm 1.0 \mathrm{~m} / \mathrm{s}$, at $24-48 \mathrm{~h}$ after stenting mean PSV was $1.1 \pm 0.4 \mathrm{~m} / \mathrm{s}(p<0.05)$, and at 30 days $1.1 \pm 0.3 \mathrm{~m} / \mathrm{s}(p<0.05)$. Maximal end-diastolic velocity (EDV) was $0.85-3.5 \mathrm{~m} / \mathrm{s}$, mean $1.4 \pm 0.5 \mathrm{~m} / \mathrm{s}$, at $24-48 \mathrm{~h}$ after stenting mean EDV was $0.3 \pm 0.1 \mathrm{~m} / \mathrm{s}(p<0.05)$, and at 30 days $0.4 \pm 0.1 \mathrm{~m} / \mathrm{s}(p<0.05)$. No restenosis or thrombosis was observed. Angiographic stenosis decreased from $82.9 \pm 9.1 \%$ (range: $61-97 \%)$ to $19.3 \pm 7.3 \%$ (range: $0-34 \%$ ) ( $p<0.05$ ).

Conclusions: The CAS using the Roadsaver stent seems to be safe and effective. Further studies involving larger patient populations and longer follow-up are needed.
\end{abstract}

Key words: carotid artery stenting, Roadsaver stent, carotid artery disease, nitinol double-layer mesh stent.

\section{Introduction}

Carotid artery stenting (CAS) is an alternative to surgery, and prevention of embolization has a crucial role during the CAS procedure. The CREST (Carotid Revascularization Endarterectomy versus Stenting Trial) trial suggested a higher risk of ipsilateral strokes after CAS compared to carotid endarterectomy (CEA) by 30 days. In contrast, there was no significant difference in the incidence of ipsilateral major stroke related to CAS or CEA from 30 days until 4 years [1]. With conventional carotid stents, the risk of embolization as a result of plaque protrusion persists for 30 consecutive days until the stent is endothelialized [2]. The risk of emboli- sation leading to adverse neurological events is particularly high after stent implantation, after postdilatation and after embolic protection device (EPD) removal. For this reason, it is necessary to refine the carotid stent design [2].

Use of closed-cell rather than open-cell design stents has been, in general, associated with a reduction of the number of periprocedural adverse neurologic events, particularly in symptomatic patients [3, 4]. Proper selection of patients, the most appropriate EPD and stent type (tailored CAS) is necessary to ensure periprocedural safety $[5,6]$.

One of the recently introduced new stent designs is the double nitinol layer micromesh self-expandable

\section{Corresponding author:}

Roman Machnik, Department of Vascular Surgery and Endovascular Interventions, John Paul II Hospital, 80 Prądnicka St, $31-202$ Krakow, Poland, phone: +48 692759 471, e-mail: ramach@op.pl

Received: 25.10.2016, accepted: 18.12.2016. 
stent Roadsaver [1, 2, 7-10]. The stent has a double structure: external macromesh and internal micromesh. The smallest cell size is $375-500 \mu \mathrm{m}$. The external layer crushes the plaque, flattening it to the inner wall of the vessel. The internal layer protects against plaque protrusion and embolization thanks to the optimized micromesh density $[1,7]$.

\section{Aim}

We assessed the safety and effectiveness of percutaneous carotid stent implantation using the Roadsaver stent in the treatment of symptomatic or high-risk, extracranial carotid artery disease.

\section{Material and methods}

This is a retrospective analysis of 41 procedures using the Roadsaver stent in non-consecutive symptomatic cases ( $n=21,51.2 \%$ ) and/or in patients with high-risk stenosis ( $n=20,48.7 \%$ ). There were 31 men (age: 68.5 \pm 8.2 range: $51-84$ years) and 9 women (age: $59.6 \pm 6.2$, range: $57-72$ ) with significant (> 50\% diameter steno-

Table I. Baseline characteristics of patients

\begin{tabular}{|c|c|}
\hline Parameter & Value \\
\hline Number of patients & 40 \\
\hline Age of all patients [years] & $67.8 \pm 7.9$ \\
\hline Age of men [years] & $68.5 \pm 8.2$ \\
\hline Age of women [years] & $59.6 \pm 6.2$ \\
\hline Hypertension & $38(95 \%)$ \\
\hline Hyperlipidemia & $39(97.5 \%)$ \\
\hline Diabetes & $13(32.5 \%)$ \\
\hline Active smokers & $17(42.5 \%)$ \\
\hline Coronary artery disease & $31(77.5 \%)$ \\
\hline Previous myocardial infarction & $10(25 \%)$ \\
\hline Multivessel coronary artery disease & $8(20 \%)$ \\
\hline Previous contralateral carotid artery stenting & $9(22.5 \%)$ \\
\hline $\begin{array}{l}\text { Previous percutaneous coronary artery } \\
\text { intervention }\end{array}$ & $14(35 \%)$ \\
\hline Restenosis after carotid endarterectomy & $1(2.5 \%)$ \\
\hline Chronic renal failure & $13(32.5 \%)$ \\
\hline Peripheral artery disease & $9(22.5 \%)$ \\
\hline $\begin{array}{l}\text { Transient ischemic attack of ipsilateral } \\
\text { hemisphere in the last } 6 \text { months }\end{array}$ & $1(2.4 \%)$ \\
\hline $\begin{array}{l}\text { Stroke of ipsilateral hemisphere in the last } \\
6 \text { months }\end{array}$ & $18(44 \%)$ \\
\hline Ipsilateral amaurosis fugax in the last 6 months & $2(4.8 \%)$ \\
\hline High-risk lesion & $20(48.7 \%)$ \\
\hline
\end{tabular}

sis, DS) internal or common carotid artery (ICA or CCA) stenosis. One patient with severe, bilateral ICA stenosis underwent a sequential CAS procedure of both ICA. Highrisk ICA stenoses were defined as lesions over $25 \mathrm{~mm}$ in length, containing aneurysm, thrombus or ulceration.

The patients suffered from hypertension $(n=37)$, hyperlipidemia $(n=38)$, diabetes $(n=13)$, and coronary artery disease $(n=30)$. Moreover, 10 patients had previous myocardial infarction, 8 patients had multivessel coronary artery disease, and 9 patients had previously undergone contralateral carotid artery stenting (Table I). Carotid stenosis grade was assessed on carotid Doppler duplex ultrasound and it was subsequently verified by quantitative carotid angiography (QCA) just before CAS. The mean DS was $82.9 \pm 9.1 \%$ (range: $61-97 \%$ ). The length of the stenotic segment was from 20 to $48 \mathrm{~mm}$ (mean: $27.2 \pm 6.4 \mathrm{~mm}$ ).

Each patient was on dual antiplatelet therapy (aspirin $75 \mathrm{mg}$ and clopidogrel $75 \mathrm{mg}$ daily for at least 3 days before the procedure or loading doses of $300 \mathrm{mg}$ of aspirin and clopidogrel the day before the procedure). During CAS unfractionated heparin (100 IU/ $/ \mathrm{kg}$ ) was used.

We performed 15 procedures of right ICA stenting, 25 of left ICA stenting and one left common artery angioplasty. Proximal $(n=27)$ or distal $(n=14)$ embolic protection was applied. Guiding catheters $7 \mathrm{Fr}(n=2)$ for right radial access, $8 \mathrm{Fr}(n=2)$ or guiding sheaths $5 \mathrm{Fr}(n=3)$ or $6 \mathrm{Fr}(n=7)$ were used (Table II).

Table II. Devices used during carotid stenting with Roadsaver stents

\begin{tabular}{|c|c|}
\hline \multicolumn{2}{|c|}{$\begin{array}{l}\text { Guiding catheters: } \\
\text { - Softip XF } 7 \text { Fr }(n=2) \text { for radial access } \\
\text { - Mach Peripheral } 8 \text { Fr }(n=1) \\
\text { - HSII } 8 \text { Fr }(n=1)\end{array}$} \\
\hline \multicolumn{2}{|c|}{$\begin{array}{l}\text { Guiding sheaths: } \\
\text { - Terumo Destination } 5 \operatorname{Fr}(n=3) \\
\text { - Terumo Destination } 6 \operatorname{Fr}(n=7)\end{array}$} \\
\hline $\begin{array}{l}\text { Proximal embolic protection } \\
\text { devices: } \\
\text { - MonoMo.Ma } 8 \mathrm{Fr}(n=1) \\
\text { - Mo.Ma } 8 \operatorname{Fr}(n=25) \\
\text { - Mo.Ma } 9 \operatorname{Fr}(n=1)\end{array}$ & $\begin{array}{l}\text { Distal embolic protection } \\
\text { devices: } \\
\text { - Wirion system }(n=5) \\
\text { - Emboshield NAV }{ }^{6}(n=3) \\
\text { - Spider FX }(n=5) \\
\text { - Filter Wire EZ }(n=1)\end{array}$ \\
\hline
\end{tabular}

Predilatation:

Sizes of balloon catheter: $2.5-3.5 \mathrm{~mm}$ width diameter, mean: $2.9 \pm 0.3,15-20 \mathrm{~mm}$ length diameter, mean: $18.1 \pm 1.0 \mathrm{~mm}$ Inflation pressure: $10-16 \mathrm{~atm}$, mean: $13.0 \pm 1.5 \mathrm{~atm}$

Sizes of Roadsaver stents:

$-7.0 \mathrm{~mm}$ width $\times 25 \mathrm{~mm}$ length diameter $(n=11)$

$-8.0 \mathrm{~mm}$ width $\times 25 \mathrm{~mm}$ length diameter $(n=12)$

$-8.0 \mathrm{~mm}$ width $\times 30 \mathrm{~mm}$ length diameter $(n=11)$

$-9.0 \mathrm{~mm}$ width $\times 30 \mathrm{~mm}$ length diameter $(n=7)$

\section{Postdilatation:}

Sizes of balloon catheter: 4.5-6.5 mm width diameter, mean: $4.8 \pm 0.3 \mathrm{~mm}, 20 \mathrm{~mm}$ length diameter

Inflation pressure: $8-18 \mathrm{~atm}$, mean: $13.07 \pm 2.5 \mathrm{~atm}$ 
Direct stenting was performed in $24(58.5 \%)$ cases, whereas in 17 (41.4\%) cases predilatation with a small coronary balloon $(2.5-3.5 \mathrm{~mm})$ was required. In all cases postdilatation was performed using usually 4.5 to $5.5 \mathrm{~mm}$ diameter balloons (in one case $6.5 \mathrm{~mm}$ - during left common artery angioplasty) to optimize the angio- graphic outcome (Figures 1, 2). In each patient angiography of intracranial arteries before and comparatively after the procedure was performed.

Patients were discharged 1-2 days after the procedure with the recommendation to take aspirin indefinitely and clopidogrel $75 \mathrm{mg}$ for 3 months. In addition, in
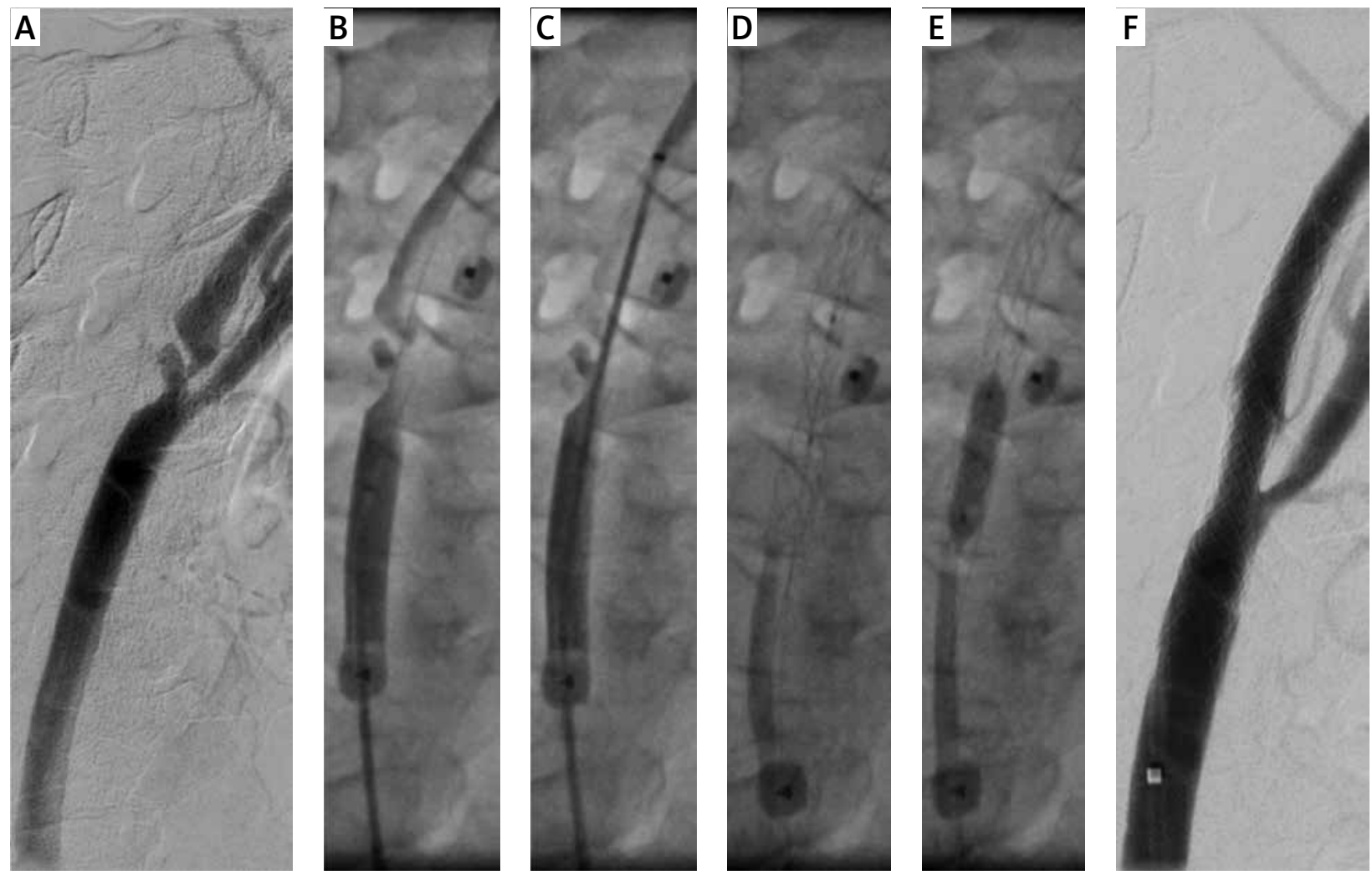

Figure 1. Severe, high-risk (aneurysm with thrombus) lesion of right ICA and the next steps of CAS using the Roadsaver stent and Mo.Ma EPD system: A - angiography, B - Mo.Ma balloons inflated in external and common carotid artery, C - stent placement, D - stent expanding - "direct stenting", E - postdilatation, F - final angiography
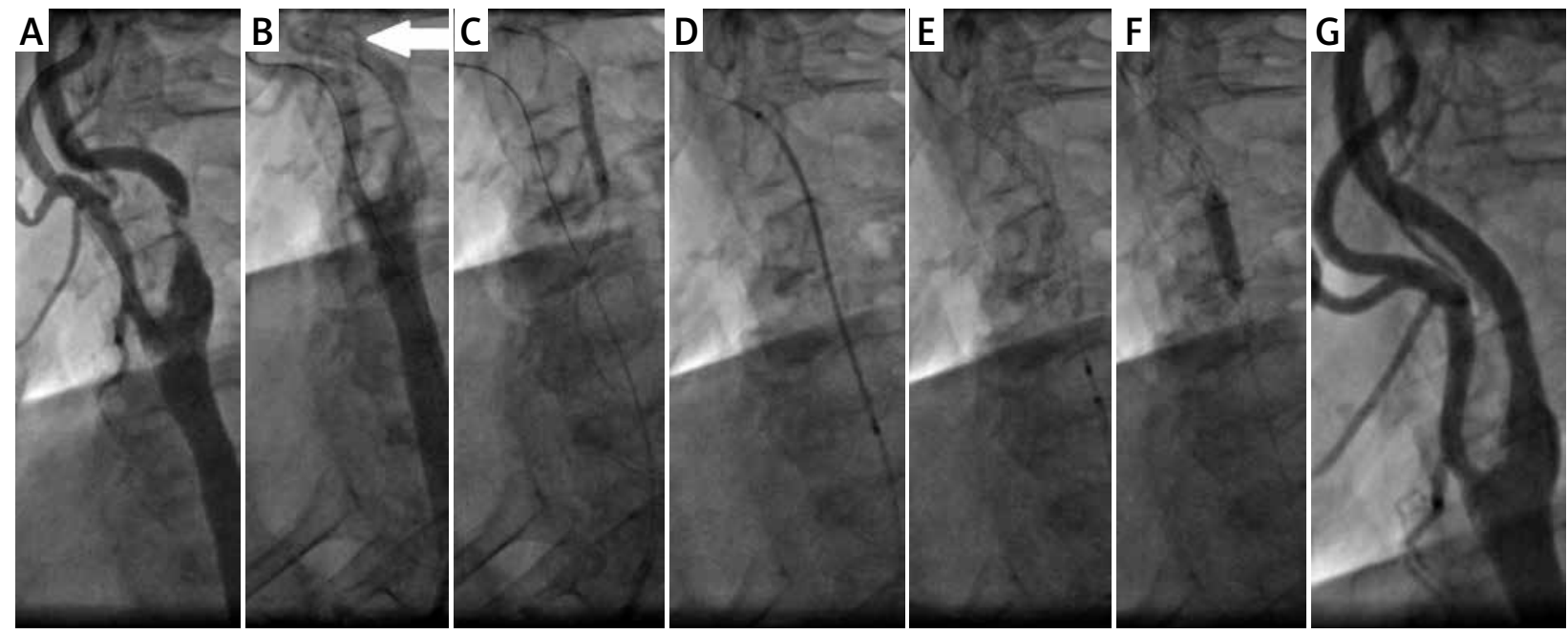

Figure 2. Severe symptomatic lesion of the left ICA and the next steps of CAS using the Roadsaver stent and distal EPD-Wirion: A - angiography, B - opening of the filter distal to the ICA stenosis (arrow), C - predilatation, D - stent placement, E - stent implantation, F - postdilatation, G - final angiography 
4 patients with atrial fibrillation vitamin $\mathrm{K}$ antagonists were continued after CAS.

\section{Statistical analysis}

The data were analyzed using the Statistica 12.0 software suite (StatSoft). The Shapiro-Wilk W test and the Kolmogorov-Smirnov test with the Lilliefors correction were used to verify the normality of distribution of results. Depending on the result of the normality of distribution, the data were analyzed using parametric or non-parametric tests. The null hypothesis $(\mathrm{HO})$ was rejected at the established level $\alpha$ lower than 0.05 .

\section{Results}

The Roadsaver stent was successfully delivered and expanded in all cases. One minor stroke occurred directly after common carotid artery intubation. In another patient transient ischemic attack (TIA) of the cerebral hemisphere ipsilateral to the ICA lesion was observed after the CAS procedure.

The postprocedural residual stenosis was $0-33 \%$ by in-house QCA (mean: $19.3 \pm 7.3 \%$ ) vs. $82.9 \pm 9.1 \%$ (range: $61-97 \%)$ before the procedure $(p<0.05)$. No stent thrombosis occurred by 30 days. The mean time of the procedure was $26 \pm 6$ (range: 18-32) min when proximal EPD was used, and for distal embolic protection the time of the procedure was $25 \pm 2$ (range: 17-30) min. Fluoroscopy time was $9.8 \pm 1.1$ (range: $8.1-11.7$ ) min.

Postprocedural carotid Doppler duplex was performed at 24-48 $\mathrm{h}$ after CAS and showed that mean peak systolic velocity (PSV) decreased from $3.9 \pm 1.0 \mathrm{~m} / \mathrm{s}$ (range: $2.0-7.0 \mathrm{~m} / \mathrm{s}$ ) to $1.1 \pm 0.4 \mathrm{~m} / \mathrm{s}$ (range: $0.5-2.1$ $\mathrm{m} / \mathrm{s})(p<0.05)$ and at 30-day follow-up mean PSV was $1.1 \pm 0.3 \mathrm{~m} / \mathrm{s}$ (range: $0.7-2.7 \mathrm{~m} / \mathrm{s})(p<0.05)$. Mean EDV at 24-48 $\mathrm{h}$ after CAS decreased from $1.4 \pm 0.5 \mathrm{~m} / \mathrm{s}$ (range: $0.85-3.5 \mathrm{~m} / \mathrm{s}$ ) to $0.3 \pm 0.1 \mathrm{~m} / \mathrm{s}$ (range: $0.17-0.6$ ) $(p<0.05)$ and at 30-day follow-up mean end-diastolic velocity (EDV) was $0.4 \pm 0.1 \mathrm{~m} / \mathrm{s}$ (range: $0.2-0.6$ ) $(p<0.05)$. No significant in-stent restenosis was observed up to 30 days.

\section{Discussion}

The micromesh double-layer self-expandable stent Roadsaver seems to be a significant step in the intraprocedural as well as postprocedural prevention of stroke. This particular type of stent is a part of new family of double-layered stents [1, 2, 7-10].

The Roadsaver stent combines the advantages of open-and closed-cell stents. Open-cell stents may cause fibrous cap rupture, plaque protrusion through the struts and higher risk of embolization, but they have better apposition to the vessel wall than the closed-cell stents. However, they have the advantage of good conformability in tortuous anatomies [2, 11, 12]. Although conventional carotid stents of closed-cell design may reduce the risk of plaque protrusion-associated adverse neurological events [3, 4, 13], this risk is not totally eliminated as the free cell area is at least $1.08 \mathrm{~mm}^{2}$.

Schnaudigel et al. showed that significant, ipsilateral changes in diffusion-weighted magnetic resonance imaging of the brain are more frequent after CAS with opencell stent than after closed-cell stent implantation $(p<$ 0.01 ) [14]. Among currently available carotid stents, the closed-cell Carotid Wallstent has the smallest size of cells (it covers the plaque and decreases the risk of plaque protrusion through the struts). However, due to the low flexibility of this stent type, stent delivery in a tortuous vessel may be difficult $[1,2]$.

In the last few years, a new type of carotid stent, which combines optimal flexibility with embolic prevention, was developed. The dual-layer micromesh design and small cell size enable the plaque to be covered and possible debris to be "trapped" between the stent scaffold and the vessel wall. Another important feature of the Roadsaver stent is its flexibility, which makes the stent deliverable even in tortuous vessels, compared to the commonly used closed-cell stents such as the Carotid Wallstent or Xact $[2,12]$. Recently published data on optical coherence tomography imaging of the Roadsaver stent showed good wall apposition without significant plaque protrusion through stent cells $[1,15]$.

The Roadsaver stent has other important aspects: it is fully re-sheathable and repositionable even after deploying $50 \%$ of the stent's length, has a $5 \mathrm{Fr}$ rapid exchange delivery system and a low profile, which enhances the crossability. One macro-mesh cell consists of 16 very small micromesh cells (size of $0.381 \mathrm{~mm}^{2}$ ) [1]. The micromesh cells are expected to prevent plaque protrusion and embolization after stent implantation. The Roadsaver stent has the advantages of both open-cell (flexibility) and closed-cell (plaque coverage) stents. The stent is available from 5 to $10 \mathrm{~mm}$ width diameter and 22 to $47 \mathrm{~mm}$ overall stent length and can accommodate vessels 1 or $2 \mathrm{~mm}$ smaller in diameter than unconstrained conditions - maximal length $67 \mathrm{~mm}$. In case of suboptimal stent deployment, repositioning is feasible.

Some authors believe that CAS using the Roadsaver stent could be performed without EPD [2, 3, 16]. This idea seems to be unreasonable, as periprocedural stroke can occur not only during stent implantation, but also at the level of introduction of the balloon catheter or stent in the unprotected diffusely diseased atherosclerotic artery. That might have been the possible cause of stroke in one of the patients in our study. Another important aspect of the micromesh double layer stent is the fact that, due to its specific design it can have an important role in the treatment of the extracranial carotid artery aneurysm or pseudoaneurysm. The unique features of micromesh can result in significant reduction of aneurysmal sac perfusion and later complete occlusion within 
11-17 days only, while the time to full occlusion of the aneurysm using other carotid stents is significantly longer - at least 6 months [8].

The introduction of mesh-covered stents might lead to further reduction of the rate of periprocedural neurological complications of CAS procedures, which is now at the level of $2.38 \%$ (thirty-day complication rate) according to the 'tailored-CAS' registry $[5,6]$, performed in our high-volume center.

Another recently introduced micromesh design - the CGuard MicroNet-covered embolic prevention carotid stent system (MN-EPS) - gives similar favorable results within 30 days. Musialek et al. performed 101 CAS procedures in symptomatic (54.4\%) or asymptomatic (45.6\%) cases. Only 1 symptomatic patient (0.9\%) suffered from minor ipsilateral stroke $24-48 \mathrm{~h}$ after CAS [17]. The registry of the CGuard stent by Shofer et al. revealed 30 CAS procedures. Possible neurological events were assessed not only by clinical symptoms (no complications were observed) but also on diffusion-weighted magnetic resonance imaging (DWI) at $48 \mathrm{~h}$ and 30 days after the procedure [10]. New ipsilateral minor ischemic lesions at $48 \mathrm{~h}$ occurred in $37 \%$ of patients (the average lesion volume was $0.39 \pm 0.08 \mathrm{~cm}^{3}$ ). The 30 -day DWI showed complete resolution of all but 1 periprocedural lesion and only 1 new minor lesion in relation to the 48-hour scan.

The recently published CLEAR-ROAD (CAS with the Roadsaver stent use) study, which included 100 patients, $31 \%$ symptomatic and EPD use was not mandatory (only $58 \%$ of patients underwent CAS with EPD), showed a low major periprocedural adverse event rate of $2.1 \%$ [16].

In our study patients were symptomatic or were at high risk of neurological embolic complications. Despite these unfavorable characteristics, a periprocedural event (minor stroke) occurred only in one patient during CAS, and it was not related to the Roadsaver because it occurred before stent deployment.

\section{Conclusions}

The CAS with the double-layer nitinol Roadsaver stent is effective and appears safe. Prospective studies involving larger numbers of consecutive patients are needed to fully demonstrate the benefit of Roadsaver in relation to conventional carotid stents.

\section{Conflict of interest}

Dr P. Pieniążek has received honoraria as a proctor from Terumo. Other authors declare no conflict of interest.

\section{References}

1. Cremonesi A, Castriota F, Secco GG, et al. Carotid artery stenting: an update. Eur Heart J 2014; 36: 13-21.

2. Hopf-Jensen S, Marques L, Preiss M, et al. Initial clinical experience with the micromesh roadsaver carotid artery stent for the treatment of patients with symptomatic carotid artery disease. J Endovasc Ther 2015; 22: 220-5.

3. De Donato G, Setacci C, Deloose K, et al. Long term results of carotid atery stenting. J Vasc Surg 2008; 48: 1431-41.

4. Bosiers M, de Donato G, Deloose K, et al. Does free cell area influence the outcome in carotid artery stenting? Eur J Vasc Endovasc Surg 2007; 33: 135-41.

5. Pieniążek P, Tekieli L, Musialek P, et al. Carotid artery stenting according to the tailored CAS algorithm is associated with a low complication rate at 30 days: data from the TARGET-CAS study. Kardiol Pol 2012; 70: 378-86.

6. Dzierwa K, Pieniążek P, Tekieli L, et al. Carotid artery stenting according to the "tailored CAS" algorithm performed in the very elderly patients: the thirty day outcome. Catheter Cardiovasc Interv 2013; 82: 681-8.

7. Kedev S, Petkoska D, Zafirowska B, et al. Safety of slender $5 \mathrm{Fr}$ transradial approach for carotid artery stenting with a novel double-layer micromesh stent. Am J Cardiol 2015; 116: 977-81.

8. Kabbasch C, Bangard C, Liebig T, et al. The dual layer Casper micromesh stent: taking advantage of flow-diverting capabilities for the treatment of extracranial aneurysm and pseudoaneurysms. Cardiovasc Intervent Radiol 2016; 39: 472-6.

9. Wisgot C, Schmidt W, Brandt C, et al. Preliminary clinical results and mechanial behavior of a new double-layer carotid stent. Endovasc Ther 2015; 22: 634-9.

10. Schofer J, Musiałek P, Bijuklic K, et al. A prospective, multicenter study of a novel mesh-covered carotid stent: The CGuard CARENET Trial (Carotid Embolic Protection Using MicroNet). JACC Cardiovasc Interv 2015; 8: 1229-34.

11. Conti M, Van Loo D, Auricchio F, et al. Impact of carotid stent cell design on vessel scaffolding: a case study comparing experimental investigation and numerical simulations. J Endovasc Ther 2011; 18: 397-406.

12. Müller-Hülsbeck S, Preuss $H$, Elhöft $H$. CAS: which stent for which lesion. J Cardiovasc Surg (Torino) 2009; 50: 767-72.

13. Bosiers M, Deloose K, Verbist J, Peeters P. Carotid artery stenting: which stent for which lesion? Vascular 2005; 13: 205-10.

14. Schnaudigel S, Groschel K, Pilgrom SM, et al. New brain lesions after carotid tenting versus carotid endarterectomy: a systemic review of the literature. Stroke 2008; 39: 1911-9.

15. de Donato G, Setacci C, Umemoto T, Reimers B. Inside of the interaction between plaque and the stent: optical coherence tomography during carotid stentig. J Endovasc Ther 2015; 22: 950-1.

16. Bosiers M, Deloose K, Torsello G, et al. The CLEAR-ROAD study: evaluation of a new dual layer micromesh stent system for the carotid artery. Eurolntervention 2016; 12: e671-6.

17. Musialek P, Mazurek A, Trystuła M, et al. Novel paradigm in carotid revascularisation: prospective evaluation of all-comer percutaneous carotid revascularisation in symptomatic and increased-risk asymptomatic carotid artery stenosis using CGuard $^{\text {TM }}$ MicroNet-covered embolic prevention stent system. Eurolntervention 2016; 12: e658-70. 